\title{
UNDERSTANDING THE FIRST-GENERATION SCHOOL-GOERS/ LEARNERS AND THEIR CHALLENGES DURING PRIMARY EDUCATION
}

\author{
Ritika Arora \\ University School of Education GGSIP University, Masters in Education; Miranda house, Delhi \\ University, B.el.ed \\ DOI: 10.46609/IJSSER.2021.v06i06.018 URL: https://doi.org/10.46609/IJSSER.2021.v06i06.018
}

\begin{abstract}
Operational definition of First-Generation School-Goers(usually referred to as First-Generation Learners) in this paper is: Students who are first in their entire generation to go to school and receive formal education or whose parents have attended the formal education system up till primary level of schooling. But why do we need to study about first-generation school-goers? What makes them different from other learners? It has been observed that they drop-out and stagnate often and if in case they reach senior secondary stage they do not absorb enough to compete with the privileged groups for further studies or employment. What are the possible reasons behind this high drop-out rate and stagnation? What problems do these learners face in classroom and school environment that leads to stagnation or dropout? What academic challenges do they face? How does their socio- economic condition affect their education? What are their parents' involvement in their education? Does evaluation process or methods of assessment has any role to play in this? How do these learners feel about education? Are there any policies to cater to their special needs? How does these policies operate or function on the ground level? What role does teachers play in this process? How do classroom- interactions affect these learners? Do these learners feel they are a part of this system or do they feel as an outcast? These are the few questions that this paper would focus on and try to find solutions to.
\end{abstract}

Keywords: First Generation Learners, First Generation School-goers, Primary- Grade Students, Formal Education, Primary education, Challenges faced by first generation learners

\section{ACADEMIC CHALLENGES INSIDE CLASSROOM}

\subsection{LANGUAGE AND LEARNING :}

During the observation and focused group discussion I found out learners are more comfortable in Hindi (reading and writing) as many of them tried reading and writing in Hindi where as they 


\section{International Journal of Social Science and Economic Research}

ISSN: $2455-8834$

Volume:06, Issue:06 "June 2021"

would just avoid or copy English but don't try reading or writing and since all their subjects were in English (English medium), they faced more difficulty in understanding all the subjects, even though they still might face difficulties in reading and writing at least they could be able to understand subjects and slowly develop the required reading and writing skills and also that will encourage them towards learning and gradually when they have gained confidence, they could be motivated and helped in learning English, as there would be a better chance of learners being able to learn a language other than their mother tongue or vernacular language.

The human mind works at its fullest potential, when it is not confined under boundaries. This is true with a growing child also, at the growing stage when the child is grasping each day many new things about the world including the medium of the communication, the language of the primary education at school, if is in congruence with the things she/he is learning at the home then his mind would better adapt new things and grasp them faster. He will probably be able to relate the two domains. Knowledge is independent of language so education in English is important but not only way to get literate.

"In 1911 Gopal Krishna Gokhale tried to make primary vernacular education free and compulsory. Education in the Government of India saw many changes in 1913 but could not be implemented because of the First World War"

"Nai-Talim, also known as BuniyadiShikshan, means basic education, defined education as, 'Education for life and education through life". Gandhiji initially focused on education of children. He firmly believed that medium of instruction of education should be in mother tongue. Education in vernacular medium will be beneficial to deprived society"

And many more commissions and educationists suggested the importance of primary education in vernacular language or mother tongue of the learner.

Therefore, inif the medium of education or the subjects during primary education are in Hindi or their home languages for the learners, they can understand the subjects better and develop confidence and will get more encouraged to learn.

\subsection{CLASSROOM INTERACTIONS}

Classroom interactions includes student- teacher interactions, student- student interactions both formal and informal ones. Both the formal and informal interactions with the teacher and fellow classmates help in the formation of 'self or self-concept' of a learner. Degrading comments from teachers when a learner is unable to answer a question like "tumheaata hi nahihoga ye , padhte/padhti hi nhiho" ; or when a learners forgets to bring something like "school kyu aateho, kaamtohkrnanhihota"; or comments from peers like "ma'am ye nhikarpyga/karpaygi"; "ma'am 


\section{International Journal of Social Science and Economic Research}

iskokuchnhiaata" ; or labelling them as "naalayak"; "bas shaitanikrneaatehai school" ; "mummy/papa ko bolo school se naam kata de nahipadhnatoh"etc. Such comments used by teachers and peers impact learners a lot, some of them might take it as a challenge (which is rare) but most of them would usually end up believing the same about themselves, it decreases whatever confidence and enthusiasm they've left inside them. This negative impact is very harmful for a young learner as he/she might get demotivated for learning or education itself, they might start to believe they're incapable of succeeding or achieving anything in classroom.

Especially, learners who are first generation school-goers who already face a lot of difficulty in adjusting to the formal school setting, who are already facing a lot of challenges, such demotivating comments will only increase the number of challenges they face on daily basis.

Whereas positive or constructive comments can help motivate learners to do better like "try karo aur jitnasmjh aa rahahai, vobatane ki koshish karo"(hints can also be given) ; "chalo koi baatnhi next time phir try karenge"; "kya koi help karega ------ apne classmate ki” ; “ aachaabhi agar aapaache se kaamkarogetohaap recess me free hojaoge and aaram se khelpaaoge, isliye try karo thodijldikrne ki" ; “issbaaraapbhoolgayehotoh share kar lo , next time yaadrakhogena ?" teacher can also address if there are any negative comments passed on by other students like saying " aachaaapkoaatahaitoh help karo apni friend/ classmate ki, I'm sure vobhiseekhjayga/jaygi” ; "sabko sab kuchtohnahiaata ,koi jaldiseekhjaatahai koi thodi der se usmekyahua, zruritoh ye hainake hum seekhjaaye". such positive comments can help learners develop and revive confidence in themselves and feel motivated to learn both inside and outside the classroom an also will help them participate more in classroom activities.

\subsection{REGULARITY/ ATTENDANCE}

Regularity or good attendance is a very determinate factor in understanding the child's academic performance as per my data and observation. As I've seen learners who are first generation school-goers and face a lot of academic issues have one thing in common which is that they are irregular in school. I believe it's a cycle irregularity in school leads to academic issues and academic issues in turn leads to irregularity, it can be explained as when a child comes irregularly to school he misses on some topics or portions of themes which leads to gap in conceptual as well as procedural knowledge, it might lead to hurdles in understanding of topics as well which are dependent on the content missed by learner and this would make it harder for the learner to understand the lessons going on in classroom and relate to them. And this gap in understanding, as it increases learner starts losing interest in studies and hence becomes more irregular in school. 


\section{International Journal of Social Science and Economic Research}

ISSN: $2455-8834$

Volume:06, Issue:06 "June 2021"

This situation if it turns adverse might lead to child facing severe issues in academics, which might affect basic literacy skills like being able to read and write in a language, and using basic arithmetic operations etc and in some cases might also lead to drop-out. From the students that I observed, Bhoomi could not read or write in any language she could not even identify numbers after 10, she was not able to perform basic skills which her classmates could do easily or with a little difficulty. When I tried to find out the reason behind this, as I talked to their class teacher I found out she kept visiting her gaon (village) with parents in class 1 which lead her to miss many classes and she spent most time of her class 2 in her village so she almost missed out on all the topics of class two and even though she attended a few classes either she could not understand them or hardly retain it and hence in class 3 she was facing so many issues and this might be the reason she was still irregular in class 3 . Similarly, all the other students who were facing issues in academics were irregular in school.

There can be various reasons for the irregularity of learners, parental support-parents are not able to avoid social commitments and that makes learners irregular in school, or maybe they face difficulty because of course content or method of teaching, or maybe they are not getting proper assistance from teacher or school like remedial classes or in class assistance, or maybe the distance to school is very long or there is less availability of transportation that learners could use to reach school, any factors or combination of factors could be possible.

\subsection{ASSESSMENT}

Assessment is an integral part of teaching learning process, to find out learners' achievement and to improve teaching learning process in classroom and also to find out level of learners. But as NCF recommends it should not be a process that creates stress, anxiety or fear among learners rather it should be done in a way that learners do not even realize that they are being assessed. But the modes of assessment used in school where observation was conducted, there were only paper- pencil tests, for formative as well as summative assessments, there were no different mode or techniques used for assessment and therefore it was hardly a holistic assessment of the learner's abilities and progress, also same criteria was used to assess all learners even those who are facing a lot of academic issues and it does not help them have a sense of achievement and they get more demotivated that they don't know or understand what to do in the test their classmates are so easily doing. The sense of achievement provides motivation and sense of failure again and again affects learner in a way that he/ she starts to believe that it is their fate to fail and that they won't be able to do good or they cannot perform well because they don't have the ability to do so. For example: When their teacher gave me their answer sheets to write the total marks, it was observed many learners have just noted down the questions and that too wrongly, some of them tried to answer but couldn't frame it correctly and they were given zeros. 


\section{International Journal of Social Science and Economic Research}

When they were asked during focused group discussion, how they feel about exams, some of them said " bilkulnahipasand"; "aachenahilagte" and when asked why they said "kyukikuchsamajhnahiaata" ; "likhnanahiaata or reading bhi" ; "mushkilhotahai" ; "kyuki zero miltahai" ; " kam marks aatehai, phirgharpedaantpadtihai", all of them had valid reasons for not liking exams in their own sense, also such assessment tell nothing about the growth of learner and hence demotivate the learners even more towards studies and learning.

Thus, it is very important to use different assessment tasks which gives a holistic view of learners development and help in building learners' confidence and help them attain a sense of achievement, so that they are motivated towards learning and performing better. Setting goals according to the individual learner will discard the unhealthy competition and help learner grow as well and achieving these small goals will build learners confidence in himself/herself/themself/themself.

During the interview with their class teacher she said that "paper-pencil mode of the assessment is the one we have known for years, and yes we can try other modes but the parents of these learners would not be able to understand such methods and practices, also such metho'ds require more time to develop as well as assess which we do not have as you have seen how every other day some notice comes and we have to work on it along with the usual administrative work, so we don't have time or parents' support to adopt such methods as we will have to make them aware of how it functions". I realized even if she would be willing to do the efforts from her side still the way system works no one will be able to understand why she is doing what she is doing and it will become another reason of stress.

\section{NON- ACADEMIC OR PSYCHOLOGICAL ISSUES}

\subsection{CONFIDENCE AND FEAR}

It is very important aspect of a learner's self-development, having confidence and faith helps learners in dealing with failures and uncomfortable situations. Apart from that it helps learner express himself or herself in classroom, share his/her opinions, problems, doubts, raise questions etc, because if a learner is not confident in himself/herself/themselves, he/ she/they will always hesitate in the fear or being wrong or being laughed upon due to that. If this fear of being wrong, guides the learner it will hinder him/her/them/them in the path of learning as the child would not express himself/herself/themselves and the doubts or queries will not come forward and hence would not be clarified. It prevents learners from speaking in the class, taking initiative, answering questions or even raising questions. Faith in teacher and fellow classmates is important for learner and for that the classroom environment should be conducive, learner should feel free and safe to express himself/herself/themself and teacher and classmates and should not 


\section{International Journal of Social Science and Economic Research}

ISSN: $2455-8834$

Volume:06, Issue:06 "June 2021"

judge learner based on his/her capabilities or abilities, each and every learner should be supported and supportive. A classroom should be a safe environment for a learner.Most of the students who were FGSGs were not very participant in class and they would avoid giving answers even to the questions which are not related to subject matter and only involve their personal experiences. Bhoomi always said "ma'am humenahipata" or "humenahiaata" and she replied this to every question I asked her (she had given up trying or had lost her confidence) after a while she started would answer if she was motivated to, which made me realize that they did not express much in class. Reasons could be various but some of them were because if they say something unusual or wrong their fellow classmates would laugh at them, and it took some time during my internship to stop this reaction. So, the fear of being mocked or feeling they are not valued enough, or that no one wants to hear them was stopping them from expressing themselves in classroom. Thus, it can be said that for learners to have confidence and for them to participate in class the teacher has to make sure the classroom environment is positive and learners feel valued and that their views and opinions are respected, learners feel safe to express themselves. All this requires a good bond among teacher and learners and mutual respect and understanding among learners. Such classroom will promote active learning, peer learning, group learning and help learners learn from each other's experiences and cooperate with each other in all tasks and activities.

\subsection{SEATING ARRANGEMENT AND CLASS SIZE}

Seating arrangement or class size might look like factors that have nothing to do with challenges faced by FGSGs but they actually so have a great impact as I realized during my internship experience. My class had 36 students in total, with some students who were very active and some who would hit others as soon as my attention deflected from them, as a teacher if I talk about "in class assistance" that can be provided to learners who face academic challenges, it was very difficult to provide them assistance as if after giving a task I start to help them one by one, other learners also need my help and since there are so many of them if I started assisting them it was impossible to get the task done in time, then I asked their peers to help them out but many learners found it very difficult and said "ma'am hum nhikarpaynge", so instead of giving them the same task as others I prepared different tasks on the same lines for them to work on according to their levels but it was not possible for each task and was very tiresome and other learners would also object at times and then I had to explain them. I realized with such a big group of learners it is very difficult to provide these learners the attention and assistance they require. Remedial classes was a very important measure that should be taken in order to help these learners. But there was no extra time or measures to do so, nor there was any guidelines by the government regarding the same. When I think about their class teacher who is so loaded with 


\section{International Journal of Social Science and Economic Research}

ISSN: $2455-8834$

Volume:06, Issue:06 "June 2021"

administrative work, for her who is already bound to complete prescribed syllabus in prescribed time, it seemed like a far-fetched idea that she could help these learners, even if she wanted to.

Also, I realized they usually try to sit in the back side of classroom unless they are made to sit in the front, I'm not sure about the reason behind this, but I feel maybe they don't want to sit near the teacher so that she couldn't see the mistakes they are making in their notebooks or that they are not able to read, maybe to avoid scolding or maybe because they fear authority or maybe they don't feel they belong in the classroom, and there could be a lot more of possibilities but there should be a bond between learners and teacher which could help the child in believing that his/her/their teacher believes in him/her/them and is there to help and accepts the child with all the problems he/she/them might be facing and is willing to help, teacher should be approachable and compassionate so that learner can express himself/herself/themself and share whatever problems they are facing inside or outside classroom.

\subsection{BEHAVIOUR}

As per my observation of FGSGs some learners were very shy, while some participated in classroom discussions others would not and some were violent, some were very conserved. So, I cannot categorize them into any behavioural category. There was one thing common among them except Rajan, no other student participated in class discussion or raise hand to answer a question and I feel since he was good in academics and he had confidence in himself, he was able to do so. To understand these behaviours of learners it was important to understand them, and for that it is necessary to talk to them or get to know them, for which we need to gain their trust and to do that it's necessary to form a bond with them. Learners face problems in their lives, to provide them an environment where they can share these problems, where they feel safe and valued, will help them in opening up and hence a teacher can find out the reasons behind different behaviours of learners.

Why is it important to understand their behaviour? During my observation I realized some learners were actually conserved and shy while some were only shy inside classroom or school, I wanted to know what made them behave differently than their nature and why did some students have violent behaviour and how to control it in classroom. After talking with learners for a while and getting to know them personally, about their families, their likes and dislikes and other different things about them, I realized that they have started listening to me, taking interest in what I say and I think it is because I took interest in their life. After this it was easier to make them take initiative or to answer questions, for learners with aggressive behaviour it became a little easier to calm them down, also I used other techniques where learners were placed in different colour coded categories based on their behaviour and their personal goals were set as mutual decision between me and them, the process was gradual but in the end all the efforts were 


\section{International Journal of Social Science and Economic Research}

ISSN: $2455-8834$

Volume:06, Issue:06 "June 2021"

worth it. Since getting to know them helped me understand them better I was able to motivate them in different ways and incentives which were different for each learner. Creating difference in their behavioural aspects also helped in building confidence in learners and changing the views of their fellow classmates towards them, after a lot of discussion and talk students stopped mocking, commenting and criticizing each other.

\section{TEACHER BURNOUT}

Burnout is intimately related to and often used interchangeably with the term stress. It was Freudburger who coined the term burnout; burnout syndrome is a result of prolonged stress, primarily- characterized by physical, emotional and attitudinal exhaustion. Teacher in a class is supposed to take care of all the learners in her class, teach them, answer to their woes, help them with their doubts, solve and stop their fights, assess them, answer the queries of their parents and above all that do all the administrative work along with finishing the prescribed syllabus in prescribed time, attend workshops, do election/other duties and the list goes on and still if a child doesn't perform well the teacher is blamed. During my observation I have seen their class teacher busy in some work or the other, sometimes she has to download and print a notice or sheet in perfect size, make posters or banners for some rally, upload the attendance online even when there is no internet facility at the school and there are some technical glitches, she has to get the work done anyhow. When asked about how she can help the FGSGs she said "with all the burden of work it sometimes becomes difficult to teach learners, even if I want to help them I can't as it requires time and patience and we don't get enough time already, to conduct their remedial classes a lot of policy level changes are required" , she also mentioned "I personally don't feel no detention policy is of any help to learners as when they reach the next grade with not enough learning and knowledge it just decreases their confidence and interest in learning,being directly promoted has also made some learners stop doing efforts to pass and it becomes more difficult to teach them over years". while talking about assessment she mentioned "paper-pencil mode of the assessment is the one we have known for years, and yes we can try other modes but the parents of these learners would not be able to understand such methods and practices, also such methods require more time to develop as well as assess which we do not have as you have seen how every other day some notice comes and we have to work on it along with the usual administrative work, so we don't have time or parents' support to adopt such methods as we will have to make them aware of how it functions". All this can help us understand the plight of a teacher in school and how stressed she is. And the question arises is she even happy at her job or frustrated? Stress by and large puts too much pressure on an individual physically and psychologically as a result prolonged stress individuals felt burnt out, it means after sometime individuals felt themselves as empty, devoid of motivation and often does not see any hope of positive change in his situation. As when asked about her job she said "it is 


\section{International Journal of Social Science and Economic Research}

ISSN: $2455-8834$

Volume:06, Issue:06 "June 2021"

not as fulfilling as I want it to be a lot of teaching- learning hours are affected due to other work ,which if done by an efficient person (who has a hang of technology) won't take up much time or efforts and would not be as draining as it is for us but we have to do it, so there is no other choice so I try to be happy in what it is", as we can clearly see she is trying to adjust to the situation and not really happy about it.There is thus a pressing need to re-examine the entire school system and redefine the terms and conditions from the point of view of the teachers. All those concerned with the school system including teacher educators, administrators, planners, policy makers and teachers themselves must work as a team to help not only those teachers who are experiencing high burnout but also to prevent the low burnout group from regressing to high burnout level

\section{PARENTAL SUPPORT}

Parental support is a combination of variables like monetary support, frequency of school visits, motivating the child to study, following up on school work and providing support in homework. It is important, how parents see education, because it determines how they support their children for education. When parents effectively internalize the fact that like other basic needs, education is essential to one's life they would ensure that the child comes to the school regularly. Regular attendance is, of course, the most important step to improving a child's educational standard.Uneducated parents fail to provide any educational, vocational or personal guidance to their children because there is no provision of appropriate educational environment at home but still, they can help learners a lot by checking up on them, following up on their performance and problems in school, sending him/her/them to school daily.

For a learner, parents can make sure there is no problem at school like the child feels safe and is not being bullied. Even if the child works with his/her/their parents after school they can make sure he/she/they does his/her/their homework and check up with teacher later, parents can help them in studies if they can, even if they can't they can make child sit to study for at least some time in a day, they can ask the child what he/she has learned at the school today and ask what all did they write in their notebooks, sometimes encourage them to share a story or poem they learned at school.

During my observation and as per my interview with their class teacher, parent of one child never comes to school even after being called for too many times to sign for receiving textbooks for the child, they showed up after two months, this child whose name is Abhishek, himself only came to school twice or thrice in a month and when he came he couldn't do any task, faced severe academic issues and did not take initiative or participate in class, remained lost in classroom. Similarly, there were some students whose parents came to school occasionally only for some work purpose and parents of some students visited school regularly or daily to pick their child but never interacted with teacher or kept check of their child's performance and talked 


\section{International Journal of Social Science and Economic Research}

ISSN: $2455-8834$

Volume:06, Issue:06 "June 2021"

to me or their class teacher while parents of Rohan and Rajan did it on a regular basis. And it might just be one of the reasons that both of them were good in academics or maybe because they were good their parents kept check but according to my interview with their class teacher she said "the learners perform well because their parents send them to school daily and even when Rajan had a fracture his father would personally help him come to school daily and take him, they are really concerned about their children's education ,Rohan used to face problems earlier but his parents kept a check on him, made him study even though they have never went to school and he improved, parents role is bigger than getting them admitted to school". And in my observation what she said about their parents' concern was true. I will not say that this is the only factor responsible for their good performance but it definitely makes a difference.

\section{POLICIES}

The Education Commission (1964-66) described the widening distinctions in educational facilities for the "classes and the masses". It considered the existing educational system as undemocratic and inconsistent with the ideals of an egalitarian society. The commission suggested that special attention be paid to the education of scheduled castes, scheduled tribes and other backward classes.

The National Policy of Education 1986, and its Program of Action (PoA) specially emphasizes "investment in the development of the young child, particularly from sections of the population in which first-generation learners predominate", (Part-V, 5.1). The NPE - 1986 further states, "First Generation learners should be allowed to set their own pace and be given supplementary remedial instruction".

RTE (Right to Education,2009) mentions first generation learners/school-goers in "disadvantaged groups" under the socially or educationally backward category. It further says "only those students are supposed to receive a special training who are admitted according to age-appropriate admissions. "To ensure that child belonging to disadvantaged group is not discriminated against and prevented from pursuing and completing education up till elementary level. For the same $25 \%$ of the seats have been reserved for EWS category and disadvantaged groups in unaided schools and they are not receiving any grants for it. Also, it says proportionate representation shall be given to parents/guardians of children belonging to disadvantaged group and weaker section."

Although all these policies acknowledge and give specifications about the needs of first generation school-goers and brings them into school environment but as we can see it doesn't make sure about how to curb the challenges that come their way inside the school, for example: when a child is admitted in school in standard/class appropriate to his/her/their age in let's say 


\section{International Journal of Social Science and Economic Research}

ISSN: $2455-8834$

Volume:06, Issue:06 "June 2021"

class 3 how will the remedial classes go on, how would he/she come at par with the level of their classmates in a time of one year, do they/they provide a special teacher to take care of such child's special needs or the class teacher is only responsible to make it happen and if she is trained to do so, does their class teacher get any relief from administrative work to make time or are any regular remedial classes arranged, does all the schools have enough staff and school counsellor to help such students and their families. There are a lot of things that plays a role in drop-out or stagnation of such learners are they anywhere taken up or addressed in policies? Is there enough manpower employed to check on the implementation of the policy, is the required understanding of the policy and are teachers and the people on ground level provided special training or the workshops required for them to understand the policy and its implementation and fulfil their roles? It is very necessary that during the formation of such policies there is enough representation of teachers and other people working at the ground level to get better inputs and data on the related subject and also qualitative and comprehensive researches should be conducted so as to understand and cater to all the needs regarding the subject. Therefore, it is important to have good comprehensive policy regarding first generation school-goers catering to all the challenges they face and keeping in mind all the factors responsible, if we really want to bring equity just getting such special needs children in school isn't enough, we need to make sure that they stay in school and learn.

\section{RESULTS AND DISCUSSIONS}

As clearly represented through the data, and it's interpretation/analysis that how various factors and challenges affect FGSGs. There are various challenges academic as well as nonacademic/psychological, where academic challenges include issues in basic reading, writing skills and basic arithmetic abilities which we can come to know about through language used and how it impacts learning, classroom interactions, regularity/attendance, assessment and nonacademic/ psychological issues include confidence level, fear, class size/ seating arrangement and behavioral aspects. Various factors like parental support, teacher burnout, policies, play different roles, some other factors such as issues in family (economic or otherwise), learner's health, distance between school and home etc. can also affect their academic performance.

I found out that as various factors come in play together and they create a huge impact, some of them might play greater role than others but all of them have their own impact. I understood that parental support and regularity has a major impact on these on these learners more than their socio- economic background as learners had mostly the similar or almost live in the same conditions as per my data. Only thing common between two students who performed well in academics and different from other nine FGSGs was their regular attendance in school and that their parents visited school regularly and stayed in touch with their teacher about their performance in school although both students had different behavioral aspects/ nature, there 


\section{International Journal of Social Science and Economic Research}

might be other reasons involved but it was not tuition or external help in academics as I asked them about it. By this I don't infer these are the only reasons but in this case they seem to be affecting more there could be more reasons which were not studied or could not be observed due to irregularity of students or other reasons, like limited number of FGSGs observed and that too from only one class in one school.

After analyzing all the factors and challenges faced by FGSGs I realized there are a lot of changes required from grass-root to the policy level, from encouraging and training teachers to help them, to conduct workshops for their parents, finally to bringing policies so that these factors and challenges could be eliminated or taken care of as much as possible.It includes providing them extra facilities like trained teachers for remedial teaching, conducting various workshops for learners, parents and teachers to help them realize all these factors and how they affect academic performance and lead to drop-out in many cases or how the language used for textbook impacts learners and content should be such as they could relate it with their lives.

All the factors that have been analysed in this study can be studied separately and in relation to each other, in details in various school contexts like other government and private schools, even a comparative study could be conducted on large scale to find out more possible factors and challenges faced by the learners and their socio- economic backgrounds, availability of resources can also be studied in detail to get a better in depth understanding of these learners and the study / researches done could be used in bringing a change at policy level. Such Studies can also be conducted at university/college level

\section{CONCLUSION}

Teachers who understand the challenges faced by these learners and are trained for it should be employed so that such learners can be properly helped and their special needs are fulfilled. Also, required changes should be made at policy levels to deal with issues such as teacher burnout, making parents aware of their roles and challenges that their children face and can be avoided, changing the language used in textbooks(medium) to make the text more relatable and understandable to learners. In service training programs should be conducted for teachers and various workshops should be conducted for parents and learners, to help them understand how to deal with various situations and challenges.

\section{REFERENCES}

- Awasthy, G. \& Khimani, V. Academic challenges faced by first generation learners in an NGO- run school vis-a-vis Government School in the Nainital District (Uttarakhand) of Northern India. Submitted for fulfilment of introduction to research course, Azim Premji University, Bangalore (2015). 
- Bhattacharyya M. \& Bhattacharyya T. ; First Generation Learner; Pratichi (India) Trust In association with: Child Rights and You (C.R.Y)

- Banerjee, J. (2012). First generation learners-caught between two worlds-with specific reference to scheduled tribes of Ranibandh block, Bankura.

- Dubule, V K(2013) ; A comparative study of habits and youth problems amongst advantaged and disadvantaged first generation and non first generation learners ; Sant Gadge Baba Amravati University

- Ghosh, S. (2014). THE SILENT EXCLUSION OF FIRST GENERATION LEARNERS FROM EDUCATIONAL SCENARIO-A PROFILE FROM PUNCHA BLOCK OF PURULIA DISTRICT, WEST BENGAL . International Journal of Developmental Research, 804-811.

- Malkani, R., \& Rose, R. (2018). Learning from the voices of first generation learners in a remote community of Maharashtra, India. International Journal of Whole Schooling, 14(2), 104-127.

- Mary.K.R; Language Difficulties of First Generation Learners in a Government Primary System.;DEDU

- Mohd. Suhail(2012) Burnout Syndrome in Government School Teachers Online

- International Interdisciplinary Research Journal, $\{$ Bi-Monthly $\}$, ISSN22499598, Volume-II, Issue-IV, July-Aug 2012

- Snell, T. P. (2008). First-Generation Students, Social Class, and Literacy . American Association of University Professors, 28-31.

- http://www.thehindu.com/opinion/op-ed/dealing-with-first-generationschoolgoers/article6802551

- https://rreducators.wordpress.com/2018/04/07/importance-of-imparting-education-invernacular-language/ 